\title{
Settlement dynamics of the coral reef fish Stegastes partitus, inferred from otolith shape and microstructure analysis
}

\author{
Harold Villegas-Hernández, Carlos González-Salas, Alfonso Aguilar-Perera*, \\ María J. López-Gómez
}

Departamento de Biología Marina, Universidad Autónoma de Yucatán, Km. 15.5, carretera Mérida-Xmatkuil, A.P. 4-116 Itzimná, C.P. 97100, Mérida, Yucatán, México

\begin{abstract}
Settlement dynamics of the bicolor damselfish Stegastes partitus (Pomacentridae) were determined by otolith shape and microstructure analysis and compared among different coral reef areas (Windward, Lagoon, and Leeward) of Chinchorro Bank, northern Meso-American Barrier Reef System, eastern Yucatan Peninsula. Estimated age, settlement time, size at settlement, and larval otolith growth rates were compared using a 2-way ANOVA with 2 fixed and orthogonal factors (reef areas and cays) with 3 levels each. Significant differences in planktonic larval duration were found, with (mean) 28.8, 30.3 and $32.7 \mathrm{~d}$ spent at Windward, Lagoon and Leeward, respectively. Individuals with shorter larval durations (at Windward) showed faster otolith growth rates and settled at relatively smaller sizes than those with longer larval durations (Lagoon and Leeward). However, there was no significant difference in otolith growth rates among reef areas, and there was no clear evidence for delay in metamorphosis. Based on both the planktonic larval duration (PLD) and the prevalent current pattern in the area, it appears that strong northwesterly currents passively transport $S$. partitus larvae into Chinchorro Bank. Larvae may enter at Windward, pass through the reef Lagoon, and leave by the Leeward. Longer PLD for $S$. partitus settling at Leeward are not due to differences in larval growth rates, but more likely to a lack of access to suitable settlement habitat by the time the larvae has passed through the reef system. An otolith shape (Fourier) analysis revealed a clear differentiation between otoliths from the 3 reef areas, suggesting that the environmental influence on otolith shape of $S$. partitus is relatively uniform, which means that this fish is affected by similar local environmental conditions within each reef area.
\end{abstract}

KEY WORDS: Chinchorro Bank - Stegastes partitus - Otolith microstructure - Planktonic larval duration $\cdot$ Settlement $\cdot$ Fourier shape analysis

Resale or republication not permitted without written consent of the publisher

\section{INTRODUCTION}

Early life history of nearly all coral reef fishes includes a dispersive, pelagic larval phase and a juvenile phase that undergoes a transition from a pelagic to a demersal existence (Leis 1991). In coral reefs, various environmental factors influence the dynamics of fish settlement not only over time in the same location but also simultaneously at different locations (Sponaugle \& Cowen 1996). Several processes during the pelagic existence usually affect growth, survival, dispersion and settlement dynamics of fish larvae. While fish larvae of most fish species may continue to grow (and die if a suitable habitat is not found) (Danilowicz 1997), the larvae of a few species are able to deliberately slow their development until encountering an ideal juvenile habitat (Sponaugle \& Cowen 1994). Various mechanisms and factors contribute to the successful transport of larvae to appropriate settlement habitats: (1) pelagic larval duration (Sponaugle \& Cowen 1994), (2) larval swimming behavior (Danilowicz 1997), (3) larval feeding rates, growth, and mortality rates (Leis 1991), 
(4) presence of conspecifics (Booth 1992) and predators (Hixon \& Beets 1993), (5) the coral species they inhabit (Jones 1988), and (6) physical processes, such as wind, tides and ocean currents (Cowen 1991).

Fish may not survive the dispersive larval stage without an appropriate transport to a given reef (Leis 1991). Recent age-based studies have identified both temporal and spatial patterns in larval supply. From the otolith microstructure, valuable information (age, planktonic larval duration, origin, growth rates, and environmental history) on early life history phases can be obtained, while very useful information may also be obtained from the otolith shape analysis (in particular from Fourier analysis). Using otolith shape data, it is possible to discriminate populations (Jónsdóttir et al. 2006), species (Stransky \& MacLellan 2005), and stocks (Friendland \& Reddin 1994). While otolith shape is markedly species-specific (Pothin et al. 2006), the otolith nucleus and shape within a species often vary across geographical areas (Campana \& Jones 1992).

The present study was designed to improve the understanding of settlement dynamics in a reef fish (Stegastes partitus) from an atoll-like coral reef system (Chinchorro Bank) in the Mexican Caribbean, eastern Yucatan Peninsula. Age, time and size at settlement, and growth rates from recently settled fish were determined using otolith microstructure analysis. Additionally, differential settlement and spatial variations in settlement were inferred using Fourier analysis on otolith shape.

\section{MATERIALS AND METHODS}

Study area. Chinchorro Bank (Fig. 1), one of the largest atoll-like reefs in the Caribbean Sea (Jordan \& Martin 1987), is an elliptical reef $40 \mathrm{~km}$ in length and $18 \mathrm{~km}$ in width located $\sim 30.8 \mathrm{~km}$ off the southeastern Yucatan Peninsula (Jordan \& Martin 1987). Chinchorro Bank has 3 sandy cays (Cayo Norte, Cayo Centro and Cayo Lobos) located on the north, central and south sides, respectively. At least 3 separate reef areas are recognized (Jordan \& Martin 1987) according to the degree of current and wave exposure: (1) Windward, a platform with an inclination of 3 to $8^{\circ}$ reaching a depth of $60 \mathrm{~m}$ and comprising a well-developed reef crest; (2) Lagoon, an open, shallow lagoon, varying from 7 to $9 \mathrm{~m}$ in depth at southern areas and 2 to $3 \mathrm{~m}$ in depth towards northern areas, with patch reefs and coral knolls gradually decreasing in number and size from south to north; and (3) Leeward, lacking a developed reef crest, and with reef structures less prominent than those in Windward area.

A sampling design was established according to reef components: 3 sites for each reef area (Windward, Lagoon and Leeward) and 3 sites for each cay (Norte, Centro and Lobos) (Fig. 1). Based on the proposed design, 2 gradients were investigated: (1) 'across-reef' gradient (east-west), compromising 3 sites for each reef area, and (2) 'along-reef' gradient (south-north), compromising 3 sites for each cay.

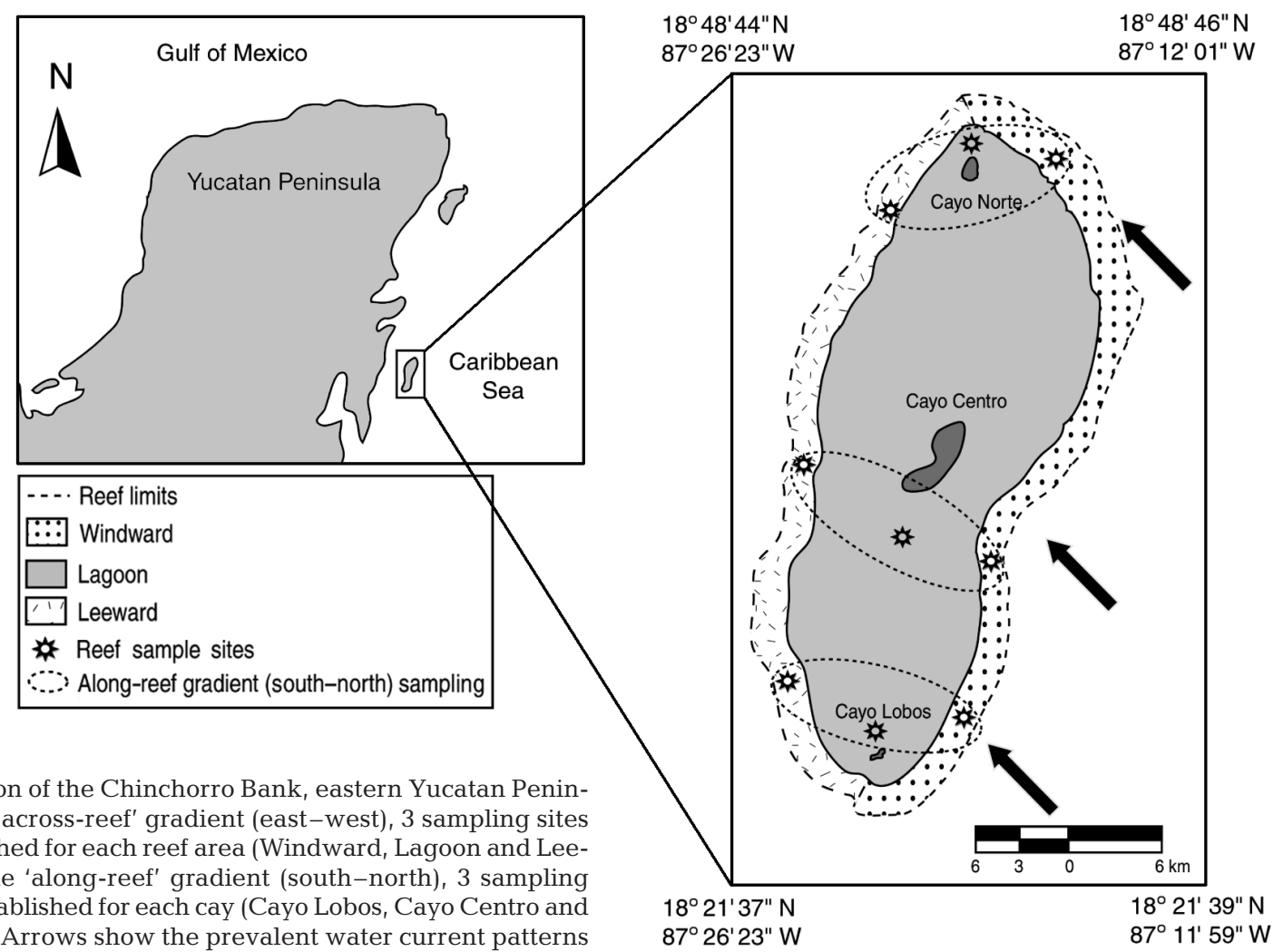

Fig. 1. Location of the Chinchorro Bank, eastern Yucatan Peninsula. For the 'across-reef' gradient (east-west), 3 sampling sites were established for each reef area (Windward, Lagoon and Leeward). For the 'along-reef' gradient (south-north), 3 sampling sites were established for each cay (Cayo Lobos, Cayo Centro and Cayo Norte). Arrows show the prevalent water current patterns 
Study species. The bicolor damselfish Stegastes partitus (Poey 1868) is one of 9 species of Pomacentridae found in the Caribbean Sea (Allen 1991). This species was a useful model for the study as it shares similar life history traits with other reef fish species: planktonic larvae and strong site fidelity from settlement to adulthood (Chittaro et al. 2006). Females deposit a clutch of $\sim 2000$ eggs on benthic substrata where males fertilize the eggs externally (Robertson et al. 1988). Larvae hatch $3 \mathrm{~d}$ after egg deposition, and begin a planktonic larval phase varying from 27 to $31 \mathrm{~d}$ (mean $=28.8 \mathrm{~d}$ ) until settlement (Robertson et al. 1988, Wellington \& Victor 1989). After settlement, individuals are relatively sedentary and occupy a relatively small territory $\left(<2 \mathrm{~m}^{2}\right)$ (Robertson et al. 1988, Chittaro et al. 2006).

Fieldwork. Fish collection was conducted in August 2005, since Stegastes partitus has its highest recruitment point during summer (Almada-Villela et al. 2003). Prior to collection, fish were anesthetized (75\% ethylic alcohol and 25\% clove oil; Ackerman \& Bellwood 2002) and then taken with a hand net. Since new recruits are $2.5 \mathrm{~cm}$ in maximum total length (AlmadaVillela et al. 2003) only individuals $<3 \mathrm{~cm}$ were considered for collection. Specimens were stored in $97 \%$ ethanol until they could be dissected in the laboratory. Morphometrics (to the nearest $10^{-1} \mathrm{~mm}$ ) for each fish, taken using calipers, included total length (TL), standard length (SL) and head length (HL). Of the 135 specimens collected (15 per site, with a size range of 1.22 to $2.81 \mathrm{~cm}$, mean $=1.56 \mathrm{~cm}$ ), only those in the range of 1.22 to $2.5 \mathrm{~cm}$ were included in the analysis; consequently, there were 126 specimens (14 per sampling site and 42 per reef area).

Otolith preparation. Under the stereomicroscope, sagittal otoliths were removed from each fish using the 'open-the-hatch-method', then otoliths were cleaned and stored dry in vials (Secor et al. 1992). Sagittal otoliths were chosen from other otolith types because of their larger size, degree of interspecific variation, and the relative ease with which the microstructures can be assessed (Secor et al. 1992). Using transmitted light, high-contrast photo images were obtained from each otolith placed on a microscope slide (for minimizing distortion errors in the normalization process, the sulcus always faced downwards and the rostrum always pointed in the same direction).

Age determination. The age (d) and the pelagic larval duration (d) were determined following standard protocols of microstructure examination (Wilson \& McCormick 1997). Mounted otoliths (with thermolabile resin Cristal Bond 590 ${ }^{\mathrm{TM}}$ in glass slides) were polished by hand, using wet lapping films (1000 to $0.3 \mu \mathrm{m})$, successively, until the core and the microincrements could be observed clearly. Thin, trans- verse sections through the nucleus of each otolith were obtained and examined with transmitted light at 400 to $1000 \times$ magnification. Images were captured using a digital still camera and measurements taken on a computer screen using the OPTIMAS imageanalysis system v. 6.1. In order to determine otolith growth rates during larval periods, the width $(\mu \mathrm{m})$ of each successive otolith increment was measured as the distance between 2 consecutive opaque zones. Otoliths displayed a prominent growth increment surrounding the primordium; the latter was used as the starting point in counting increments. Daily increments were counted twice by the same reader; counts differing no greater than $5 \%$ were averaged; those that differed by $>5 \%$ were counted a third time; if these differed by $>5 \%$ over the previous counts, the otolith was rejected.

In Stegastes partitus, otolith increments are deposited on a daily basis (Wellington \& Victor 1989, Robertson et al. 1993). The age of each specimen was determined using an increment correction of $3 \mathrm{~d}$ to the total number counted, on the assumption that the first increment was not formed until the first feeding (i.e. approximately $3 \mathrm{~d}$ after fertilization) (Campana \& Jones 1992). This corrected increment count was subtracted from the capture date to determine the hatch date or back-calculated birth date. Presumed settlement marks were identified by a sharper contrast than preceding marks (where the pattern of increment widths changes markedly and the post-settlement widths are consistently narrower than those laid down before settlement, Wellington \& Victor 1989). Increments were counted from the primordium (core) to the settlement mark, and a correction of 3 increments was added for estimating the number of days before settlement mark (or planktonic larval duration). Settlement dates were back-calculated by subtracting the number of post-settlement increments from the date of capture.

Individual fish sizes (SL) at settlement by reef area were backcalculated using the biological intercept procedure (Campana \& Jones 1992), given by $L_{a}=L_{\mathrm{c}}+$ $\left(O_{a}-O_{\mathrm{c}}\right)\left(L_{\mathrm{c}}-L_{0}\right)\left(O_{\mathrm{c}}-O_{0}\right)^{-1}$, where $L_{a}$ is the estimated fish length at age $a, L_{c}$ is fish length (standard length) at capture, $O_{\mathrm{C}}$ is otolith radius at capture, $L_{0}$ and $O_{0}$ are the size of the fish and otolith at the biological intercept, respectively. The biological intercepts of $L_{0}$ and $O_{0}$ were fixed at $2.2 \mathrm{~mm}$ fish length and $0.10 \mathrm{~mm}$ otolith radius, respectively.

Otolith shape (Fourier) analysis. The method of elliptic Fourier shape analysis (Kuhl \& Giardina 1982) fits an arbitrary closed curve to an ordered set of data points in a 2-dimensional plane, with any desired degree of precision, and generates a set of shaperepresentative variables to be used in statistical com- 
parisons. Using this analysis, any outline is reduced to its $x$ - and $y$-projection, and expressed by Fourier expansions as an infinite sum of successive waves of cosines with an amplitude and an angle. The amplitude of the wave is the elliptic Fourier shape descriptor, also termed the harmonic (Kuhl \& Giardina 1982, González-Salas \& Lenfant 2007). The contribution of each harmonic, with both $x$ - and $y$-variations, is an ellipse. The harmonics for the $x$ - and $y$-coordinates are computed by using the incremental changes in the $x$ and $y$ direction.

In this study, the otolith (shape) contour of Stegastes partitus was used to calculate the elliptic Fourier descriptors (EFDs) using the Shape 1.2 software (Iwata \& Ukai 2002); this software provides a normalization process of the EFD (Kuhl \& Giardina 1982). The number of harmonics required can be estimated from the average Fourier Power spectrum (FP) which provides a measure of the amount of shape information (Renaud et al. 1996, Pothin et al. 2006). The amplitudes of a harmonic are calculated for $\mathrm{A}^{2}+\mathrm{B}^{2}+\mathrm{C}^{2}+\mathrm{D}^{2}$. For the $n$th harmonic, the Fourier Power $\left(\mathrm{FP}_{n}\right)$ is given by the expression: $\mathrm{FP}_{n}=\left(A_{n}^{2}+B_{n}^{2}+C_{n}^{2}+D_{n}^{2}\right) / 2$, where $A_{n}, B_{n}$ $C_{n}$ and $D_{n}$ are the Fourier coefficients of the $n$th harmonic. Then, the cumulated power percentage $\left(\mathrm{FP}_{\mathrm{c}}\right)$, defined by $\mathrm{FP}_{\mathrm{c}}=\Sigma_{1}^{n} \mathrm{FP}_{n}$, is calculated (Pothin et al. 2006). The number of harmonics that reach $>99 \%$ of the total variation from FP is the total number of harmonics required (Pothin et al. 2006). In Chinchorro Bank, 15 harmonics were required for describing the complex morphology of the sagittal otolith of $S$. partitus (Fig. 2). The first harmonic represents the initial

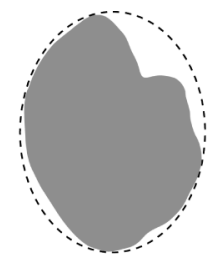

1 harmonic

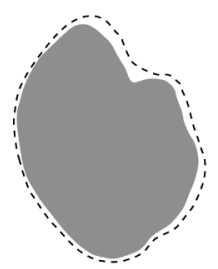

9 harmonics

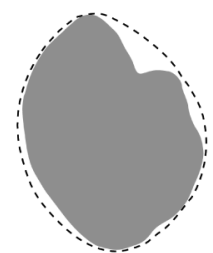

3 harmonics

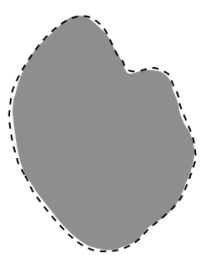

12 harmonics

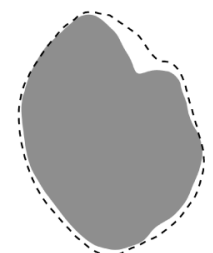

6 harmonics

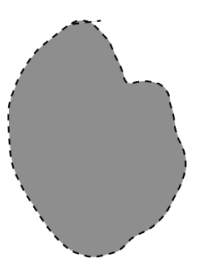

15 harmonics
Fig. 2. Stegastes partitus. Reconstruction of otolith shape by addition of Fourier shape components (harmonics). After adding each harmonic, the resultant shape was plotted. Thus, the shape ' 6 harmonics' represents the total sum of shape information contained in the first 6 harmonics, and so on. The first 15 harmonics of the elliptical Fourier series were enough to describe the otolith shape point or mean radius of the shape, thus it is not relevant to the analysis (Renaud et al. 1996); consequently, the coefficients corresponding to this harmonic were eliminated from the analysis.

Statistical analysis. A 2-way ANOVA, including 2 fixed and orthogonal factors (reef areas and cays) with 3 levels each, was performed to investigate whether the age, the planktonic larval duration(s) (PLD), the larval otolith growth rates and the back-calculated size (SL) of Stegastes partitus at settlement differed in any of the 2 gradients. Where applicable, a post-hoc Tukey's HSD multiple comparison test was used to determine the nature of significant differences (Zar 1996). Data were examined for normality and homogeneity of variances, and subsequently $\log _{\mathrm{e}}$ transformed if these criteria were not satisfied (Zar 1996).

Otolith data shape descriptors (amplitudes) were used to determine differences in otolith shapes among reef areas (Windward, Lagoon, and Leeward). All comparisons were conducted using a permutational multivariate analysis of variance (PERMANOVA; Anderson 2005) which allows testing the simultaneous response of one or more variables to one or more factors in the ANOVA experimental design. This allows partitioning of the multivariate variation (defined by the distance of measure used) according to individual factors in any fully balanced multi-way ANOVA design to estimate the statistical probabilities associated with differences between levels of each factor (Anderson 2001). PERMANOVA was based on the Bray-Curtis dissimilarity measure (4999 random permutations and 95\% confidence). When PERMANOVA was significant at $95 \%$ confidence, the levels of each factor were investigated through a posteriori pair-wise comparisons using 4999 random permutations to obtain $\mathrm{p}$-values. For investigating any evidence of significant differences in the along-reef gradient, this procedure was also conducted among cays (Norte, Centro, and Lobos).

Linear discriminant function analyses (Blackith \& Reyment 1971) were used to support the PERMANOVA in determining differences among reef areas. A data array of the harmonic coefficients was used; each of the 14 harmonics considered was defined by 4 coefficients (14 harmonics $\times 4$ coefficients). Therefore, each otolith was described by 56 variables. Mahalanobis' generalized distance $\left(\mathrm{D}^{2}\right.$; Mahalanobis 1936$)$ was used to characterize the differences in the otolith shape among reef areas. The performance of discriminant functions was evaluated using Cohen's Kappa statistic, which provides an objective means of calculating the chance-corrected percentage of agreement between actual and predicted group memberships. Values of Kappa range from 0 to 1 , with 0 indicating the discriminant analysis yields no improvement over chance, and 1 indicating perfect agreement (Titus et al. 1984). 


\section{RESULTS}

\section{Early Life history traits}

Based on back-calculated birth dates, newly settled Stegastes partitus larvae hatched from late June to mid July, peaking between July 3 and July 5 in all 3 reef areas (Fig. 3). Statistical analyses revealed that fish were not significantly different in age among reef areas (ANOVA, $F_{2,121}=2.94, \mathrm{p}=0.0542$. PLD ranged from 24 to $32 \mathrm{~d}$ (mean $=28.8 \mathrm{~d}), 26$ to $36 \mathrm{~d}(30.3 \mathrm{~d})$, and 26 to $39 \mathrm{~d}(32.7 \mathrm{~d})$ at the Windward, Lagoon and Leeward sites, respectively (Figs. $3 \& 4$ ), and differed significantly from each other (ANOVA, $F_{2,121}=25.45, \mathrm{p}<0.0000$ ). Tukey's HSD post-hoc test showed significant differences in PLD for all pairwise comparisons (Fig. 4). Fish at the Windward site had significantly shorter PLD than fish at the Lagoon and Leeward sites, while fish at the Lagoon site had significantly shorter PLD than fish at the Leeward site.

Estimated larval otolith growth rates ranged between 1.32 and $12.23 \mu \mathrm{m} \mathrm{d}^{-1}$, with growth being gen- erally faster at the Windward $\left(\right.$ mean $\left.=7.91 \mu \mathrm{m} \mathrm{d}^{-1}\right)$, intermediate at the Lagoon $\left(6.98 \mu \mathrm{m} \mathrm{d}^{-1}\right)$ and slower at the Leeward (6.59 $\left.\mathrm{um} \mathrm{d}^{-1}\right)$ sites (Fig. 5). However, larval otolith growth trajectories were not significantly different among the reef areas (ANOVA, $F_{2,111}=2.66$, $\mathrm{p}=0.0743$ ). The relationship of SL and otolith length (OL) of newly settled larvae was well described by a simple linear regression suggesting a proportionality between otolith growth and fish somatic growth in all 3 reef areas: Windward $\left(\mathrm{r}^{2}=0.8357, \mathrm{p}<0.000, \mathrm{n}=42\right)$, Lagoon $\left(\mathrm{r}^{2}=0.8891, \mathrm{p}<0.000, \mathrm{n}=42\right)$ and Leeward $\left(r^{2}=0.8426, p<0.000, n=42\right)$ (Fig. 6). Using the biological intercept method, size (SL) at settlement was backcalculated in all 3 reef areas: Windward $\left(\mathrm{r}^{2}=0.8432, \mathrm{p}\right.$ $<0.000, \mathrm{n}=42)$, Lagoon $\left(\mathrm{r}^{2}=0.9064, \mathrm{p}<0.000, \mathrm{n}=42\right)$ and Leeward $\left(\mathrm{r}^{2}=0.9485, \mathrm{p}<0.000, \mathrm{n}=42\right)$ (Fig. 7). There were differences in size at settlement among reef areas (ANOVA, $\left.F_{2,121}=23.79, \mathrm{p}=0.0000\right)$. Fish were settling at smaller sizes at Windward (mean SL = $1.05 \mathrm{~cm}$ ), intermediate sizes at Lagoon (mean SL $=1.11$ $\mathrm{cm})$ and larger sizes at Leeward (mean SL $=1.21 \mathrm{~cm}$ ) (Fig. 8).
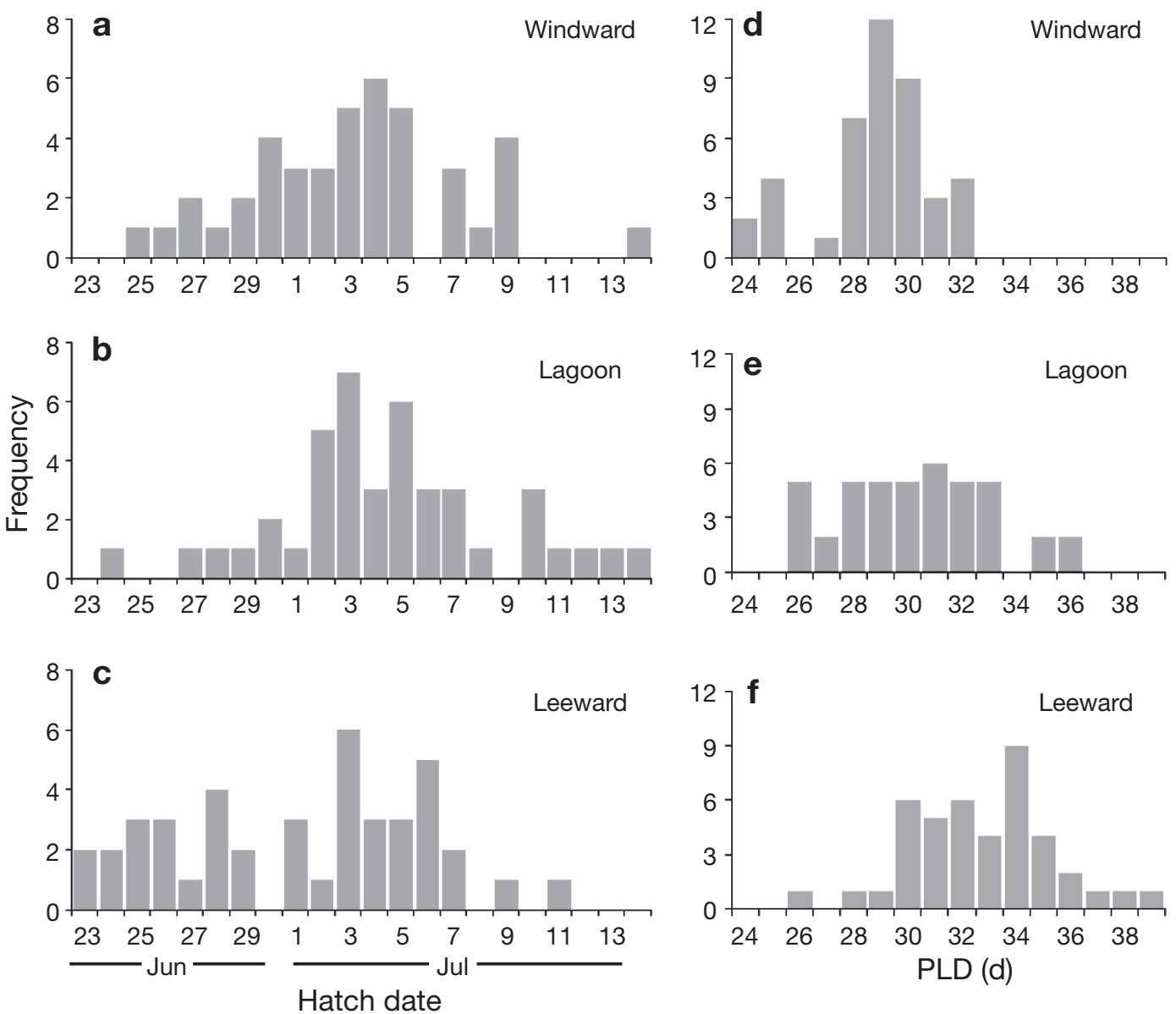

Fig. 3. Stegastes partitus. Frequency distributions of $(a, b, c)$ hatch date and $(d, e, f)$ planktonic larval duration (PLD) of newly settled fish collected at the $(\mathrm{a}, \mathrm{d})$ Windward, $(\mathrm{b}, \mathrm{e})$ Lagoon and $(\mathrm{c}, \mathrm{f})$ Leeward sites $(\mathrm{n}=42$ for each site) 


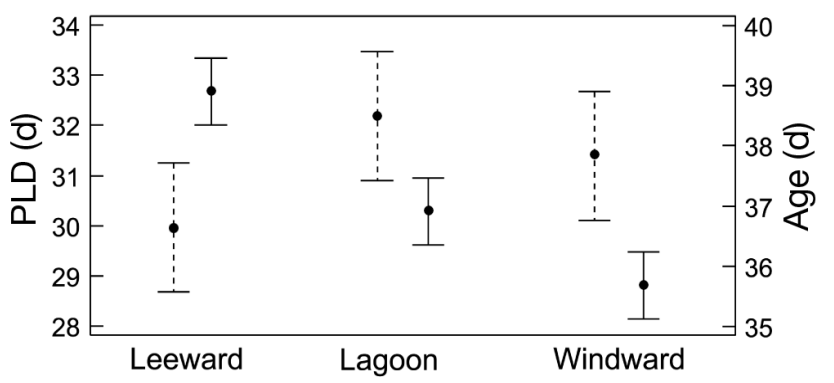

Fig. 4. Stegastes partitus. Mean and 95\% Tukey's HSD intervals for age (dashed line) and planktonic larval duration PLD (solid line) at the Windward, Lagoon and Leeward sites. Means are significantly different where the intervals do not overlap

On the other hand, when the along-reef gradient (among cays) was explored, none of the statistical analyses on age (ANOVA, $F_{2,121}=1.99, \mathrm{p}=$ 0.1406), PLD (ANOVA, $F_{2,121}=0.26, \mathrm{p}=$ 0.7707 ), larval otolith growth rates (ANOVA, $F_{2,111}=2.35, \mathrm{p}=0.0814$ ) and size at settlement (ANOVA, $F_{2,121}=0.28, \mathrm{p}=0.7599$ ) were found to be significantly different.

\section{Statistical Fourier shape analysis}

There were significant differences among reef areas (PERMANOVA, $F_{2,123}=15.459, \mathrm{p}=$ 0.0002) (Table 1). Pairwise comparisons showed that reef areas (Windward, Lagoon and Leeward) were significantly different from each other (Table 1). However, there was no evidence of significant difference among cays (Norte, Centro, Lobos) (PERMANOVA, $F_{2,123}=$ 1.771, $\mathrm{p}=0.1294$ ) (Table 1).

The linear discriminant analysis showed differences among reef areas (Fig. 9). The first 2 canonical discriminant functions accounted for $>80 \%$ of the total variation among groups. The classification success of the discriminant analysis (Table 2) indicated a strong separation among reef areas, with the F-test associated to Wilks' lambda being highly significant $\left(\lambda=0.1809, F_{120,128}=1.4414, \mathrm{p}=0.0211\right)$. In the classification matrix, each case is placed in the group where its classification function value is largest. The Windward, Lagoon and Leeward areas $(37,36$, and 36 ind., respectively) were correctly classified. In total, $87 \%$ of individuals were correctly classified. Results from the Cohen's Kappa procedure (0.80) confirmed the high rates of classification success obtained by the discriminant analysis, indicat- ing that the classification efficiency was $80 \%$ better than would have occurred by chance alone (Table 2). The Malahanobis squared distance test $\left(D^{2}\right)$ showed that the less distant centroids were between the Lagoon and Windward sites $\left(\mathrm{D}^{2}=4.7\right)$, while the more distant centroids were observed between the Windward and Leeward sites $\left(\mathrm{D}^{2}=8.1\right.$ ) (Fig. 9).

\section{DISCUSSION}

\section{Age and planktonic larval duration}

While otolith growth trajectories revealed no clear evidence of changes in the reduction of otolith growth in the late-larval stages (Fig. 5), which often indicates a delay of metamorphosis (Wellington \& Victor 1989, Cowen 1991), no difference in otolith growth rate

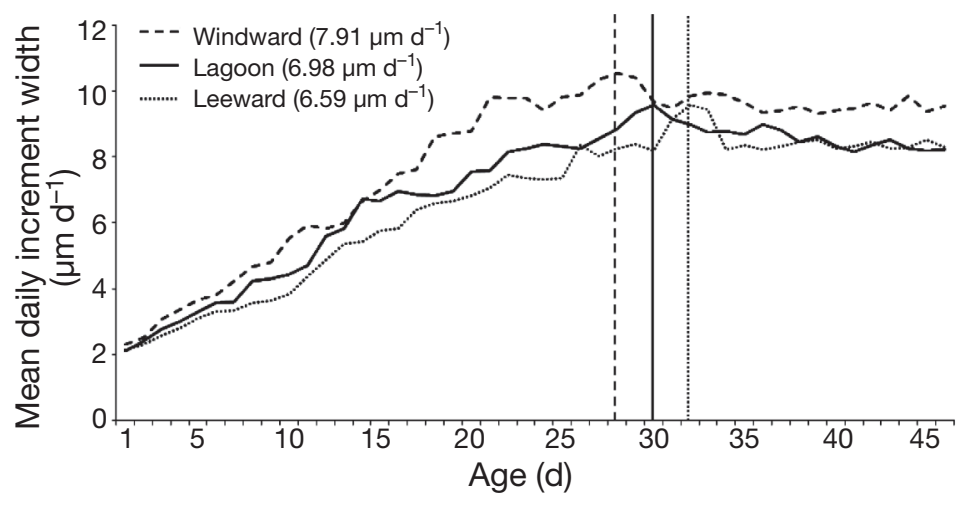

Fig. 5. Stegastes partitus. Mean daily increment widths from crosssections of sagitta from 15 newly settled fish per reef area (Windward: dashed line; Lagoon: solid line; and Leeward: dotted line) plotted against the capture date. Mean otolith growth rate $\left(\mu \mathrm{m} \mathrm{d}^{-1}\right)$ for the 15 ind. used from each reef area are given. Vertical lines represent the mean settlement age for each reef area

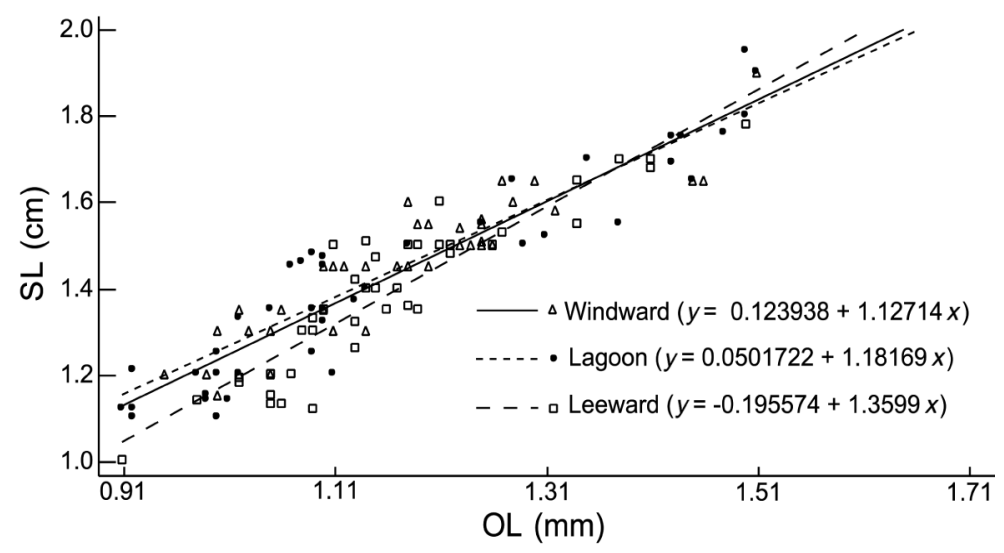

Fig. 6. Stegastes partitus. Simple linear regression of otolith length (OL) and standard length (SL) for newly settled bicolor damselfish at Windward $\left(\mathrm{r}^{2}=0.8357, \mathrm{p}<0.000, \mathrm{n}=42\right)$, Lagoon $\left(\mathrm{r}^{2}=0.8891, \mathrm{p}<0.000\right.$, $\mathrm{n}=42)$ and Leeward $\left(\mathrm{r}^{2}=0.8426, \mathrm{p}<0.000, \mathrm{n}=42\right)$ sites 


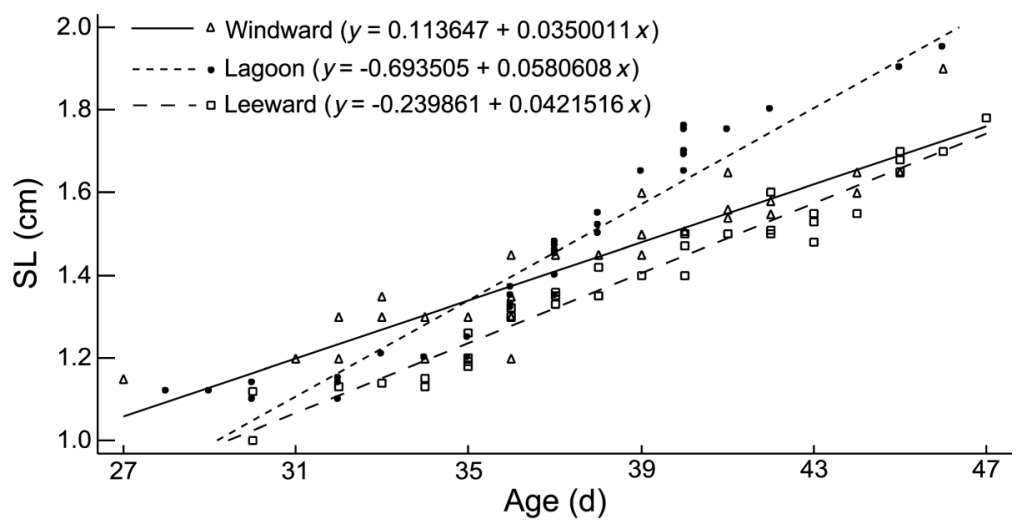

Fig. 7. Stegastes partitus. Simple linear regression of standard length (SL) and age (d) for newly settled bicolor damselfish captured at Windward $\left(\mathrm{r}^{2}=\right.$ 0.8432, $\mathrm{p}<0.000, \mathrm{n}=42)$, Lagoon $\left(\mathrm{r}^{2}=0.9064, \mathrm{p}<0.000, \mathrm{n}=42\right)$ and Leeward $\left(\mathrm{r}^{2}=0.9485, \mathrm{p}<0.000, \mathrm{n}=42\right)$ sites

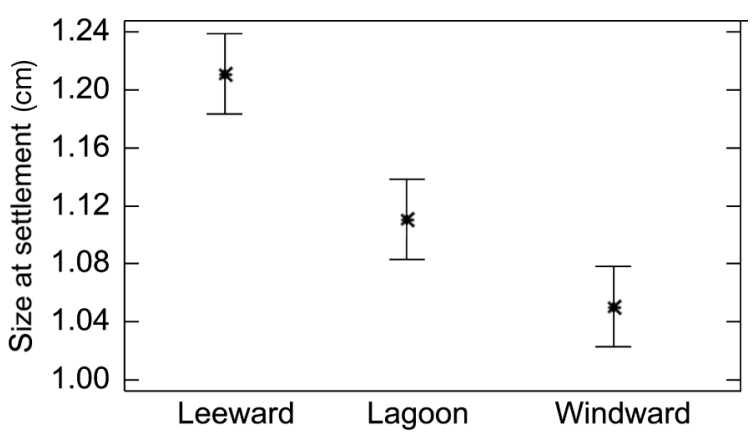

Fig. 8. Stegastes partitus. Mean and 95\% Tukey's HSD intervals for back-calculated size (standard length, SL) at settlement at Windward, Lagoon and Leeward sites (mean $=1.05$, $1.11,1.21 \mathrm{~cm}$, respectively). Means are significantly different where the intervals do not overlap

among reef areas was evident. This suggests that the Stegastes partitus larvae occupied similar water masses when hatching. Despite similar larval otolith growth trajectories, PLD showed a significant degree of variation among reef areas $(28.8 \pm 2.1,30.3 \pm 2.8$ and $32.7 \pm 2.8 \mathrm{~d}$ for Windward, Lagoon and Leeward, respectively). Fish with significantly shorter larval durations (at Windward) showed faster otolith growth rates and settled at relatively smaller sizes than those larvae with longer larval durations (at Lagoon and Leeward) (Figs. 3, 4 \& 8). Typically, fastergrowing larvae are thought to be smaller at settlement because they spend a shorter period in the plankton (Searcy \& Sponaugle 2000). Therefore, this trend of S. partitus in Chinchorro Bank (shorter sizes at settlement) and the significant differences in age at settlement for the Windward, compared to the Lagoon and Leeward sites, suggest that food and habitat availability, rather than growth, determined the timing of settlement. Similar findings (Searcy \& Sponaugle 2000, Denit $\&$ Sponaugle 2004) support the suggestion that the PLD is related to larval growth, since fastergrowing larvae often settle earlier and at shorter sizes. Denit \& Sponaugle (2004) found that larval otolith growth trajectories were generally similar for larvae of gray snapper Lutjanus griseus from different sites and years (2000 and 2001); however, the mean PLD was $1 \mathrm{~d}$ longer for fish from North Carolina than those from southern sites (South Florida) in both years. They suggested that patterns of larval and juvenile growth, coupled with recruitment dynamics across the latitudinal gradient, are consistent with the northward Gulf Stream transport of larvae from southern spawning sites.

Oceanographic features may also explain differences in PLD at different reef areas. For example, if Stegastes partitus were transported northwest by the Caribbean current, a small time-lag may have been associated with finding a suitable settlement habitat. There is a slightly longer western PLD difference (2 d) between $S$. partitus collected at each reef area, and the average current speed in the Lagoon of Chinchorro Bank $\left(\sim 0.045 \mathrm{~m} \mathrm{~s}^{-1}\right.$ in summer; Ezer et al. 2005, Navarrete 2006); thus, the larvae would be transported by the current through $7.8 \mathrm{~km}$ during those $2 \mathrm{~d}$. Considering

Table 1. PERMANOVA and associated pairwise a posteriori comparisons between levels for the factor 'Region' using Fourier descriptors (amplitudes) as variables, and 4999 random permutations with a $95 \%$ confidence. Two group sources were analyzed: 'Across-reef' gradient (east-west), with 3 levels (reef areas): Windward, Lagoon, and Leeward; and 'along-reef' gradient (south-north) with 3 levels (cays): Norte, Centro, and Lobos. Significant p-values are shown in bold

\begin{tabular}{|c|c|c|c|c|c|c|}
\hline Source and factor & $F$ & $\mathrm{df}$ & $\mathrm{p}$ & Pair & $t$ & $\mathrm{p}$ \\
\hline \multicolumn{7}{|l|}{ Across-reef } \\
\hline \multirow[t]{3}{*}{ Reef areas } & 15.4599 & 2,123 & 0.0002 & Windward vs. Lagoon & 2.846 & 0.002 \\
\hline & & & & Windward vs. Leeward & 5.058 & $<0.000$ \\
\hline & & & & Lagoon vs. Leeward & 3.073 & 0.002 \\
\hline \multicolumn{7}{|l|}{ Along-reef } \\
\hline \multirow[t]{3}{*}{ Cays } & 1.7711 & 2,123 & 0.1294 & Norte vs. Centro & 0.511 & 0.831 \\
\hline & & & & Norte vs. Lobos & 1.636 & 0.061 \\
\hline & & & & Centro vs. Lobos & 1.540 & 0.087 \\
\hline
\end{tabular}




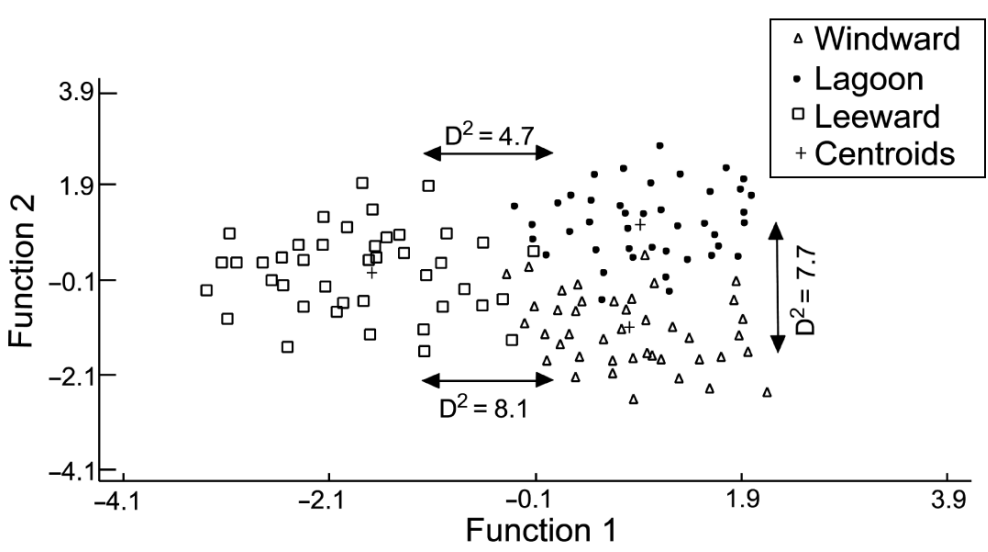

Fig. 9. Stegastes partitus. Canonical discriminant analysis based on the Fourier coefficients describing an otolith. The correct classification percentage of Windward, Lagoon and Leeward sites was 88, 86 and 86\%, respectively. The Malahanobis distances $\left(\mathrm{D}^{2}\right)$ between centroids are indicated

that the distance between the reef sample sites was $\sim 6$ to $7 \mathrm{~km}$, we suggest this small time difference in mean PLD is influenced by the current regimes and availability of a suitable settlement habitat. Thus, the variable nature of the PLD in $S$. partitus is probably a response to a range of food and habitat availabilities. A fast growth may be coupled with a strategy of remaining in high food areas (Leis 1991). In Chinchorro Bank, as the larvae are transported by currents throughout the reef they may have fewer options to settle following optimum environmental cues; however, the Windward site may represent the best settlement reef area due its well-developed and defined reef structures (Jordan \& Martin 1987). In Stegastes partitus, fish in better condition at settlement have higher chances of survival after settlement (Booth \& Hixon 1999, Wilson \& Meekan 2001). Vigliola \& Meekan (2002) found that fish that survived size-selective mortality 1 mo after settlement were individuals showing faster growth during the planktonic stage, suggesting that fast growth may not only provide a survival advantage at settlement but may also have the potential to influence post-settlement survivorship in reef fishes.

In Chinchorro Bank, due to the prevalence of the Caribbean current (average speed $0.5 \mathrm{~m} \mathrm{~s}^{-1}$ ) and its direction during summer (Ezer et al. 2005), planktonic larvae may travel $1200 \mathrm{~km}$ in about $28 \mathrm{~d}$ (mean time just before larvae reach the Windward site of Chinchorro Bank). Interactions between larval behavior and the real Caribbean current regimes would provide variation around this estimate. Rough calculations indicate that the relevant spawning grounds of Stegastes partitus would be located approximately at 1,210 km southeast of the Chinchorro Bank, close to the Caribbean coast of Panama. This is in accordance with Robertson et al. (1993), who reported spawning grounds on the Panama coast for 6 species of damselfishes, including $S$. partitus. Consequently, it is possible that our back-calculations may reflect the present conditions of settlement dynamics of this pomacentrid in the region, however, further studies on both genetics and stock assessment are needed to support these suggestions.

\section{Otolith shape analysis}

The discriminant analysis indicated a clear difference in otolith shape among reef areas (Windward, Lagoon and Leeward), with $87 \%$ of individuals correctly classified. According to Friedland \& Reddin (1994), classification values of more than $75 \%$ are acceptable. In this study, the data showed rates of accuracy classifications from 86 to $88 \%$ (Table 2) which suggests that the variability in otolith shape could be a good tool for regional and local discrimination in Stegastes partitus.

In Chinchorro Bank, the otolith shape of Stegastes partitus did not show a linear trend for the along-reef gradient; however, for the across-reef gradient there were differences (Table 1) demonstrating the consistency in otolith shape among locations within each reef area. While the immediate environmental characteristics where $S$. partitus were collected (Windward, Lagoon and Leeward) are not known in detail, the characteristics may vary due to the location in relation to wave exposure and depth. This suggests that the influence of the environment on otolith shape is relatively uniform among reef areas but not among cays.

Table 2. Linear discriminant analysis using Fourier harmonics as variables for shape analysis. Classification matrix for the reef areas (Windward, Lagoon, and Leeward)

\begin{tabular}{|lcccccc|}
\hline Region & N & Windward & Lagoon & Leeward & \% Correct classification & Cohen's Kappa \\
\hline Windward & 42 & 37 & 3 & 2 & 88 & 0.81 \\
Lagoon & 42 & 2 & 36 & 4 & 86 & 0.80 \\
Leeward & 42 & 1 & 5 & 36 & 86 & 0.80 \\
Total & 126 & 40 & 44 & 42 & 87 & 0.80 \\
\hline
\end{tabular}


The apparent uniformity may be facilitated by relatively homogeneous post-settlement processes within each reef area. In general, it is assumed that fish that encounter the same kind of environmental conditions produce otoliths having similar patterns in growth and, consequently, in shape. Campana \& Casselman (1993) suggested that environmental effects are generally more influential on otolith shape as this changes in response to differences in growth rate. This could be the case for $S$. partitus in Chinchorro Bank; individuals from similar reef areas may be affected by similar local environmental conditions which in turn influence otolith shape. Using the Fourier analysis, Gagliano \& McCormick (2004) analyzed the influence of feeding history on otolith shape using a variety of experimental feeding treatments. They found that differences in otolith shape are influenced by recent feeding history just before, during, and after recruitment. Our data indicate that the environmental conditions of settlement areas of $S$. partitus are not homogeneous throughout the Chinchorro Bank, and these conditions may have a profound effect on aspects of the juvenile and adult ecology of $S$. partitus.

\section{CONCLUSIONS}

Our findings suggest that differences in the settlement patterns of Stegastes partitus at Windward, Lagoon, and Leeward sites of the Chinchorro Bank are consistent with a passive northwest transport of larvae promoted by the Caribbean current. On the other hand, longer PLD for $S$. partitus settling at the Leeward site are not due to differences in larval growth rates, but more likely to a lack of access to suitable settlement habitat by the time the larvae is passing throughout the reef system. The overall results are consistent with the fact that larvae settle, regardless of their size, as soon as they reach a suitable settlement reef habitat; otherwise, the larvae will continue growing and simply die if they fail to encounter a reef. Relatively uniform local environmental conditions among reef areas influencing growth, such as temperature and food availability, may be the basis for the observed differences in otolith shape. While other studies have emphasized the utility of the otolith shape analysis in differentiating populations, stocks, and species, the present study suggests that otolith shape can be used to discriminate much finer-scale events, such as differential settlement on a reef system. Further studies, combining age, growth, and otolith shape data with studies of otolith microchemistry, genetic markers (microsatellites) and larval transport models are needed to gain a better understanding on the settlement dynamics and population connectivity of $S$. partitus.
Acknowledgments. We especially thank C. A. VillegasSánchez for her invaluable field assistance collecting the specimens for this study and R. Lecomte-Finiger (Université de Perpignan, France) for providing us with lapping films for polishing the otoliths. We also thank the members of the Comisión Nacional de Áreas Naturales Protegidas (CONANP) in Chinchorro Bank, whose field logistic assistance made the study possible.

\section{LITERATURE CITED}

Ackerman JL, Bellwood DR (2002) Comparative efficiency of clove oil and rotenone for sampling tropical reef fish assemblages. J Fish Biol 60:893-901

Allen GR (1991) Damselfishes of the world. Mergus Publishers, Melle

Almada-Villela PC, Sale PF, Gold-Bouchot G, Kjerfve B (2003) Manual of methods for the MBRS synoptic monitoring system: selected methods for monitoring physical and biological parameters for use in the Mesoamerican region. Mesoamerican Barrier Reef Systems Project (MBRS), Belize City

Anderson MJ (2001) A new method for non-parametric multivariate analysis of variance. Austral Ecol 26:32-46

Anderson MJ (2005) PERMANOVA: permutational multivariate analysis of variance, a computer program. Department of Statistics, University of Auckland

Blackith RE, Reyment RA (1971) Multivariate morphometrics. Academic Press, London

Booth DJ (1992) Larval settlement patterns and preferences by domino damselfish Dascyllus albisella Gill. J Exp Mar Biol Ecol 155:85-104

Booth DJ, Hixon MA (1999) Food ration and condition affect early survival of the coral reef damselfish, Stegastes partitus. Oecologia 121:364-368

Campana SE, Casselman JM (1993) Stock discrimination using otolith shape analysis. Can J Fish Aquat Sci 50: 1062-1083

Campana SE, Jones CM (1992) Analysis of otolith microstructure data. In: Stevenson DK, Campana SE (eds) Otolith microstructure examination analysis. Can Spec Publ Fish Aquat Sci 117:73-100

Chittaro PM, Gagnon J, Fryer BJ (2006) The differentiation of Stegastes partitus populations using lapillar and sagittal otolith chemistry. J Fish Biol 68:1909-1917

Cowen RK (1991) Variation in the planktonic larval duration of the temperate wrasse Semicossyphus pulcher. Mar Ecol Prog Ser 69:9-15

Danilowicz BS (1997) The effects of age and size on habitat selection during the settlement of a damselfish. Environ Biol Fishes 50:257-265

Denit K, Sponaugle S (2004) Growth variation, settlement, and spawning of gray snapper across a latitudinal gradient. Trans Am Fish Soc 133:1339-1355

Ezer T, Thattai DV, Kjerfve B, Heyman WD (2005) On the variability of the flow along the Meso-American Barrier Reef system: a numerical model study of the influence of the Caribbean current and eddies. Ocean Dyn 55:458-475

Friedland KD, Reddin DG (1994) Use of otolith morphology in stock discriminations of Atlantic salmon (Salmon salar). Can J Fish Aquat Sci 51:91-98

Gagliano M, McCormick MI (2004) Feeding history influences otolith shape in tropical fish. Mar Ecol Prog Ser 278:291-296

> González-Salas C, Lenfant P (2007) Inter-annual variability and intra-annual stability of the otolith shape in European 
anchovy Engraulis encrasicolus (Linneus, 1758) in the Bay of Biscay. J Fish Biol 70:35-49

Hixon MA, Beets JP (1993) Predation, prey refuges, and the structure of coral-reef fish assemblages. Ecol Monogr 63:77-101

Iwata H, Ukai Y (2002) Shape: a computer program package for quantitative evaluation of biological shapes based on elliptic Fourier descriptors. J Hered 93:384-385

Jones GP (1988) Experimental evaluation of the effects of the habitat structure and competitive interactions on the juveniles of two coral reef fishes. J Exp Mar Biol Ecol 123: $115-126$

Jónsdóttir IG, Campana SE, Marteinsdottir G (2006) Otolith shape and temporal stability of spawning groups of Icelandic cod (Gadus morhua L.). J Mar Sci 63:1501-1512

Jordan E, Martin E (1987) Chinchorro: morphology and composition of a Caribbean atoll. Atoll Res Bull 310:1-27

Kuhl FP, Giardina CR (1982) Elliptic Fourier features of a closed contour. Comput Graph Image Process 18:236-258

Leis JM (1991) The pelagic stage of reef fishes: the larval biology of coral reef fishes. In: Sale PF (ed) The ecology of fishes on coral reefs. Academic Press, San Diego, CA, p $183-230$

Mahalanobis PC (1936) On generalized distance in statistics. Proc Natl Inst Sci India 2:49-55

Navarrete AJ (2006) Drift cards trajectory released at Banco Chinchorro, Quintana Roo. Universidad y Ciencia 22: 89-93

Pothin K, González-Salas C, Chabanet P, Lecomte-Finiger R (2006) Distinction between Mulloidichthys flavolineatus juveniles from Reunion Island and Mauritius Island (south-west Indian Ocean) based on otolith morphometrics. J Fish Biol 69:38-53

Renaud S, Michaux J, Jeager JJ, Auffray JC (1996) Fourier analysis applied to Stephanomys (Rodentia: Muridae) molars: nonprogresive evolutionary pattern in a gradual lineage. Paleobiology 22:255-265

Robertson DR, Green DG, Victor BC (1988) Temporal coupling of production and recruitment of larvae of a

Editorial responsibility: Matthias Seaman,

Oldendorf/Luhe, Germany
Caribbean reef fish. Ecology 69:370-381

Robertson DR, Schober UM, Brawn JD (1993) Comparative variation in spawning output and juvenile recruitment of some Caribbean reef fishes. Mar Ecol Prog Ser 94:105-113

Searcy SP, Sponaugle S (2000) Variable larval growth in a coral reef fish. Mar Ecol Prog Ser 206:213-226

Secor DH, Dean JM, Laban EH (1992) Manual for otolith removal and preparation for microstructural examination. The Electric Power Research Institute and the Belle W. Baruch Institute for Marine Biology and Coastal Research, University of South Carolina, Columbia, SC

Sponaugle S, Cowen RK (1994) Larval distributions and recruitment patterns of two Caribbean gobies (Gobiidae) constrasting early life histories in demersal spawners. Mar Biol 120:133-143

Sponaugle S, Cowen RK (1996) Larval supply and patterns of recruitment for two Caribbean reef fishes, Stegastes partitus and Acanthurus bahianus. Mar Freshw Res 47: 433-447

Stransky C, MacLellan SE (2005) Species separation and zoogeography of redfish and rockfish (genus Sebastes) by otolith shape analysis. Can J Fish Aquat Sci 62:2265-2276

Titus K, Mosher JA, Williams BK (1984) Chance-corrected classification for use in discriminate analysis: ecological applications. Am Midl Nat 111:1-7

Vigliola LM, Meekan G (2002) Size at hatching and planktonic growth determine post-settlement survivorship of a coral reef fish. Oecologia 131:89-93

Wellington GM, Victor BC (1989) Planktonic larval duration of one hundred species of Pacific and Atlantic damselfishes (Pomacentridae). Mar Biol 101:557-567

Wilson DT, McCormick MI (1997) Spatial and temporal validation of settlement marks in the otoliths of tropical reef fishes. Mar Ecol Prog Ser 153:259-271

Wilson DT, Meekan MG (2002) Growth-related advantages for survival to the point of replenishment in the coral reef fish Stegastes partitus (Pomacentridae). Mar Ecol Prog Ser 231:247-260

Zar JH (1996) Biostatistical Analysis. Prentice-Hall

Submitted: July 16, 2007; Accepted: December 17, 2007

Proofs received from author(s): January 23, 2008 